\title{
E-Selectin Supports Neutrophil Rolling In Vitro under Conditions of Flow
}

\author{
Omid Abbassi, ${ }^{*}$ Takashi K. Kishimoto, ${ }^{\star}$ Larry V. McIntire, * Donald C. Anderson, ${ }^{3}$ and C. Wayne Smith" \\ *Biomedical Engineering Laboratory, Institute of Biosciences and Bioengineering, Rice University, Houston, Texas 77251; \\ ${ }^{\ddagger}$ Department of Immunology, Boehringer Ingelheim Pharmaceutical Inc., Ridgefield, Connecticut 06877; ${ }^{\S}$ Discovery \\ Research, Upjohn Laboratories, Kalamazoo, Michigan 49001; and "Section of Leukocyte Biology, \\ Department of Pediatrics, Baylor College of Medicine, Houston, Texas 77030
}

\begin{abstract}
E-selectin was evaluated for its ability to support neutrophil adhesion under conditions of flow. At a wall shear stress of 1.85 dyn $/ \mathrm{cm}^{2}$, neutrophils were found to attach to E-selectin expressed on the apical surface of $L$ cell monolayers. The initial intercellular contact was most often evidenced by neutrophils rolling on the monolayer at a mean rate of $\simeq 10 \mu \mathrm{m} / \mathrm{s}$. Anti-Eselectin monoclonal antibody, CL2/6, inhibited this interaction by $>90 \%$. Rolling neutrophils often transiently stopped, but in contrast to the behavior on stimulated endothelial cells, they remained spherical in shape and did not migrate on or beneath the monolayer. A possible contribution of neutrophil L-selectin to this interaction was indicated by the findings that anti-L-selectin monoclonal antibody, DREG-56, inhibited E-selectindependent adhesion under flow by $>65 \%$, and there was a highly significant correlation between surface levels of $\mathrm{L}$-selectin and E-selectin-dependent adhesion under flow. E-selectin also appeared to support neutrophil adhesion to IL-1 $\beta$-stimulated endothelial cells under conditions of flow, but it accounted for only $\simeq 30 \%$ of the level of adherence, in contrast to L-selectin which accounted for $>65 \%$. Thus, both L-selectin and E-selectin can support neutrophil adhesion at wall shear stresses that preclude intercellular adhesion molecule-1-dependent adhesion, and they participate in neutrophil adherence to stimulated endothelial cells under conditions of flow. (J. Clin. Invest. 1993. 92:2719-2730.) Key words: adhesion • CD18 • intercellular adhesion molecule-1 • neutrophils • selectins
\end{abstract}

\section{Introduction}

Intravital microscopy has revealed neutrophils rolling along the endothelial lining of postcapillary venules (1-8). This phenomenon is particularly evident during the early stages of an acute inflammatory process, where rolling neutrophils often stop, change shape, and migrate through the endothelium. Leukocyte rolling may represent a necessary phase for efficient localization of the neutrophils at inflammatory sites, but the molecular mechanisms that account for this phenomenon have not been completely defined. Lewinsohn et al. (9) and Jutila et al. ( 10) provided evidence that L-selectin expressed on

Portions of this work were presented at a Symposium, "Blood Cell Activation and Inflammation," held 29-31 May 1992, Rochester, NY.

Address reprint requests to Dr. C. Wayne Smith, Section of Leukocyte Biology, Texas Children's Hospital Clinical Care Center, Suite 1130, 6621 Fannin, MC 3-3272, Houston, TX 77030-2399.

Received for publication 5 August 1992 and in revised form 1 July 1993.

J. Clin. Invest.

(C) The American Society for Clinical Investigation, Inc. $0021-9738 / 93 / 12 / 2719 / 12 \$ 2.00$

Volume 92, December 1993, 2719-2730 neutrophils participates in the accumulation of these leukocytes at sites of acute inflammation. Kishimoto et al. (11) proposed that L-selectin was necessary for the initial adhesion to endothelium and is subsequently downregulated as adherent neutrophils are stimulated to emigrate. In support of this concept, we found that mAbs against L-selectin reduced by $>60 \%$ attachment of neutrophils to activated endothelial cell monolayers under conditions of flow, and there was a direct correlation between adhesion at a wall shear stress of $1.85 \mathrm{dyn} / \mathrm{cm}^{2}$ and the levels of L-selectin on the neutrophil surface (12-14). Anti-L-selectin mAbs used in a rabbit model of inflammation (15), and polyclonal antibodies against L-selectin in a rat model (16) reduced the quantity of rolling neutrophils in postcapillary venules. Recombinant soluble L-selectin also exhibited antiinflammatory activity through some unknown mechanism when administered to mice systemically (17). Apparently L-selectin-mediated adhesion, under conditions of flow, complements the function of CD18-integrins in that L-selectin contributes to the initial adhesion and CD18-integrins support transmigration of adherent neutrophils.

Adhesion of previously unstimulated neutrophils to endothelial cell monolayers in vitro occurs only if the endothelial cells have been stimulated (e.g., with TNF $\alpha$ or IL-1 $\beta)(12,13$, 18 ). The newly upregulated factor(s) on the endothelial cell with which L-selectin interacts are unknown. In addition to stimulating increased synthesis of intercellular adhesion molecule-1 $(\text { ICAM-1 })^{1}(19,20)$, cytokine treatment of endothelial cells induces expression of the two other members of the selectin family P-selectin and E-selectin $(21,22)$, and a L-selectin ligand (23). In the present report we address the hypothesis that E-selectin can support the initial adhesion of neutrophils to activated endothelial cells under conditions of flow in vitro at wall shear stresses beyond which ICAM-1/CD18 mechanisms can function. E-selectin appears on the cell surface within $2 \mathrm{~h}$ after cytokine stimulation (21), and has been shown to support neutrophil adherence under static (21) and nonstatic (i.e., rotating, agitation) conditions in vitro (23). In addition, anti-E-selectin has been found to reduce neutrophil accumulation in inflammatory sites in rats $(24,25)$ and monkeys in vivo (25). No evidence has been published, though, showing that E-selectin can catch neutrophils flowing past endothelial cells at venular wall shear rates.

\section{Methods}

Isolation of neutrophils. Neutrophils were purified from citrate anticoagulated, dextran-sedimented venous blood samples of healthy adult

1. Abbreviations used in this paper: HUVEC, human umbilical vein endothelial cells; ICAM-1, intercellular adhesion molecule-1; LELAM, L cells transfected with cDNA for human E-selectin; L-ICAM, L cells transfected with $\mathrm{cDNA}$ for human ICAM-1; sLe ${ }^{\mathrm{x}}$, sialyl Lewis $\mathrm{X}$. 
donors over Ficoll-Hypaque gradients and were suspended in Dulbecco's PBS (GIBCO, Grand Island, NY), pH 7.4, containing $0.2 \%$ dextrose as previously described (13). Isolated neutrophils were maintained at $4^{\circ} \mathrm{C}$ for up to $4 \mathrm{~h}$ at a concentration of $10^{7} / \mathrm{ml}$. Neonatal neutrophils were isolated from cord blood. Placentas from vaginal deliveries of healthy mothers in the absence of general anesthetics and with Apgar scores of $>8$ at 1 and 5 min were collected in the delivery suites. Venous blood was collected, citrate anticoagulated, diluted with equal amounts of PBS, dextran sedimented, and isolated as described above. Hematological staining (NeatStain, Biochemical Sciences, Bridgeport, $\mathrm{NJ}$ ) revealed that $>95 \%$ of the isolated polymorphonuclear leukocytes were neutrophils. Of these cells typically $>99 \%$ were viable (excluded tryphan blue) and practically all possessed unstimulated spherical geometry.

In some experiments, neutrophils were activated by stimulation with chemotactic tripeptide FMLP ( $10 \mathrm{nM})$ at room temperature for 15-25 min. At the end of the activation period the cell suspension was either diluted 10 times with culture medium M199 (preheated to $37^{\circ} \mathrm{C}$ and $\mathrm{pH}$ of 7.4 in tissue culture incubator) or washed twice in PBS to remove the stimulant, and incubated an additional $10 \mathrm{~min}$ without stimulant. With either method the abrupt decrease in the concentration of the chemotactic factor caused a reversal in neutrophil shape from bipolar to slightly ruffled and spherical. This step was important since bipolar neutrophils are at a disadvantage when compared with unstimulated spherical neutrophils for adhesion and especially rolling under conditions of flow.

In some experiments, isolated neutrophils at $10^{7}$ cells $/ \mathrm{ml}$ were incubated with neuraminidase (Boerhinger-Mannheim Biochemicals, Indianapolis, IN) at $0.1 \mathrm{U} / \mathrm{ml}$ for $30 \mathrm{~min}$ at room temperature, washed, and resuspended in PBS. Control neutrophils used in these experiments were exposed to similar steps without exposure to neuraminidase.

Monoclonal antibodies. The mAbs used in these studies include preparations of $\operatorname{IgG}$, IgM, and $\mathrm{F}\left(\mathrm{ab}^{\prime}\right)_{2}$ fragments. The anti-CD18 mAbs, R15.7 (IgG1) (26) and TS1/ 18 (IgG1) (27), were prepared as previously described. An mAb to L-selectin, DREG-56 (IgG1), was prepared as previously described (28). CL2/6 (IgG1), anti-human E-selectin was prepared as previously described (29). $F\left(a b^{\prime}\right)_{2}$ fragments of CL2/6 were used in antibody inhibition assays (30). Antisialyl Lewis $X\left(s^{x} e^{x}\right) m A b(I g M)$ was prepared from CsLeX cell line obtained from American Type Culture Collection (Rockville, MD). All mAbs used in this study were titered using flow cytometry (FACScan, Becton Dickinson \& Co., Mountain View, CA) to determine the concentration that saturated surface binding sites of unstimulated and stimulated cells as previously described $(12,13)$. TS $1 / 18, \mathrm{R} 15.7$, and DREG-56 were used at $10 \mu \mathrm{g} / \mathrm{ml}$ and CL2/6 F( $\left(\mathrm{ab}^{\prime}\right)_{2}$ was used at 20 $\mu \mathrm{g} / \mathrm{ml}$.

Preparation of human umbilical vein endothelial cells. Human umbilical vein endothelial cells (HUVEC) were harvested and characterized as to acetylated LDL binding and factor VIII expression according to established techniques as previously described (31). Primary venular endothelial cells from 5-10 umbilical cords were pooled and plated in M199 containing 10\% FCS and 10\% BSA (Hyclone Laboratories, Logan, UT), 5\% penicillin-streptomycin (GIBCO) 5\% Fungizone (GIBCO), $0.1 \mathrm{mg} / \mathrm{ml}$ heparin (Sigma Chemical Co., St. Louis, MO), and endothelial cell growth factor (Sigma), and maintained for 3-4 d at $37^{\circ} \mathrm{C}, 5 \% \mathrm{CO}_{2}$ humidified atmosphere. Visually confluent monolayers on gelatin $(0.1 \%$, Sigma $)$ and fibronectin $\left(5 \mu \mathrm{g} / \mathrm{cm}^{2}\right.$, Calbiochem Corp., San Diego, CA) coated $24 \times 50-\mathrm{mm}$ rectangular glass coverslips (special order from Bellco, Vineland, $\mathrm{NJ}$ ) were prepared from first passage cells harvested with $0.05 \%$ trypsin and $0.02 \%$ EDTA in PBS (GIBCO). HUVEC were pretreated with IL- $1 \beta$ (Calbiochem) at $3 \mathrm{U} / \mathrm{ml}$ for $4 \mathrm{~h}$ in ELISA and at $5 \mathrm{U} / \mathrm{ml}$ for $3 \mathrm{~h}$ in adhesion assays.

Transfection of $L$ cells. Human E-selectin cDNA (generous gift of Dr. B. Seed, Harvard Medical School, Boston, MA) was subcloned into the mammalian expression vector pMRB101 (32), which contains a human cytomegalovirus promoter and the Escherichia coli gpt gene. L cells were transfected by electroporation and selected for resistance to mycophenolic acid (33). Cells stably expressing E-selectin were selected by three rounds of staining with the CL2 anti-E-selectin mAb followed by fluorescence-activated cell sorting of the highest $10 \%$ of the population. L cells stably transfected with ICAM-1 were a generous gift of Drs. A. deFougerolles and T. A. Springer (Center for Blood Research, Boston, MA).

Adherence assay under conditions of flow. Neutrophil adhesion to IL- $1 \beta$-stimulated endothelial cells was assessed as previously described $(18,34)$. Briefly, passage one HUVEC were grown to confluency on gelatin-fibronectin-coated coverslips, stimulated with IL-1 $\beta(5 \mathrm{U} / \mathrm{ml})$ for $3 \mathrm{~h}$, rinsed in serum-free medium (M199), mounted in parallel plate flow chambers, and perfused for 5-10 min with M199 (rinse step). Neutrophils were placed at room temperature for 15-25 min, then stimulated with FMLP, and/or incubated with mAb when indicated. The concentration of the mAbs was maintained throughout the experiment. The neutrophil suspensions were passed through the chamber at a wall shear stress of $1.85 \mathrm{dyn} / \mathrm{cm}^{2}$, and the interaction of neutrophils with the endothelial monolayer was observed under phasecontrast microscopy (Diaphot-TMD, Nikon Inc., Garden City, NY) for $10 \mathrm{~min}$ and recorded on video tape. A minimum of 10 digitized frames (Perspective Systems, Inc., Houston, TX) of different fields of view from the last minute of the videotaped experiments (9-10 min in neutrophil perfusion period) were used to determine the number of neutrophils that remained in contact with the monolayer. Neutrophils adherent on the luminal surface of the monolayer possessed spherical geometry and appeared as phase-bright objects whereas those migrated to the subluminal space were flattened and appeared as phase dark objects as previously documented (34). Adhesion was defined as the total number of neutrophils in contact with endothelium (rolling or stationary on the luminal surface and migrated to the subluminal space). The number of migrated neutrophils represented those adherent neutrophils that had migrated and the ratio of migrated neutrophils to total adherent neutrophils was used in calculation of the percent of adherent neutrophils transmigrated.

Adhesion assays with monolayers of L cells transfected with cDNA for human E-selectin (L-ELAM) were carried out essentially as described in endothelial cell experiments with the modification that, since L-ELAM monolayers contained phase-bright refractile bodies, the field of view was maintained at the same location (in the middle of the flow chamber) throughout the 10-min neutrophil perfusion period. Entire experiments were recorded on videotape and analyzed using digitized background subtraction imaging techniques, where the initial frame of the monolayer was digitized and continuously subtracted from the image of the field of view. Under these conditions the neutrophils adherent or rolling on the monolayer appeared as phase-bright objects against a gray back ground. The number of the neutrophils adherent (rolling and stationary) at the end of the 10-min neutrophil perfusion period was used as the adhesion value and converted to neutrophils per square millimeter.

Monolayers were preincubated with CL2/6( $\left.\mathrm{Fab}^{\prime}\right)_{2}$ at $20 \mu \mathrm{g} / \mathrm{ml}$ for $30 \mathrm{~min}$ at $37^{\circ} \mathrm{C}, 98 \%$ humidity, $5 \% \mathrm{CO}_{2}$ incubator. Anti-E-selectin $\mathrm{mAb}$ was also maintained in rinse media and neutrophil suspension. All flow experiments were performed at $37^{\circ} \mathrm{C}$.

Rolling velocity measurements. Tapes from experiments on $\mathrm{L}$ ELAM monolayers were used in the analysis of rolling velocity. Recordings from 5 to $10 \mathrm{~min}$ in neutrophil perfusion were used in a digital imaging program which grabbed and digitized two frames $1-5 \mathrm{~s}$ apart and subtracted the later image from the earlier one. The program was set to show all null values as gray, positive values as white, and negative values as black. When there was no change in the image and the two frames were identical, the subtracted image would appear as a uniform gray screen. When neutrophils, which appeared as phase-bright objects in the original recording, moved from one location to a another, the initial location would appear as a dark spot (since the final image was darker than the initial image in that location) and the second location would appear as a bright spot ( since the final image was brighter than the initial image in that location ). An example of this analysis is shown in Fig. $2 A$. This Figure is the collection of five of subtracted images 
made at intervals of $1,2,3,4$, and $5 \mathrm{~s}$. The average displacement of the neutrophil was measured in pixels, divided by time interval between the frames, and converted to micrometers per second. The average of the rolling velocities was used as representative of the rate of rolling for that experiment.

Data presentation. Results are presented as means $\pm 1 \mathrm{SD}$, and $n$ represents the number of separate experiments. Statistical assessments were made using paired two-tailed Student's $t$ test on adhesion values, except when indicated. An unpaired two-tailed Student's $t$ test was used to compare percent inhibitions.

\section{Results}

\section{E-selectin-dependent neutrophil adhesion under conditions of flow}

Murine $\mathrm{L}$ cells, transfected with human E-selectin cDNA (LELAM cells), when grown to confluent monolayers, exhibited E-selectin expression levels comparable to those of the IL- $1 \beta$ stimulated ( 3 h) HUVEC monolayers (optical density val- ues \pm SD: HUVEC, 1.619 \pm 0.201 ; L-ELAM, $1.445 \pm 0.195, n$ $=3$ ). Immunofluorescence studies of confluent monolayers revealed a similar distribution of E-selectin, though stimulated HUVEC monolayers were somewhat more uneven than LELAM with randomly distributed endothelial cells that were clearly brighter than average. Association of isolated neutrophils with confluent L-ELAM cell monolayers at a wall shear stress of $1.85 \mathrm{dyn} / \mathrm{cm}^{2}$ closely resembled that of the IL- $1 \beta-$ stimulated HUVEC monolayers. On L-ELAM, $619 \pm 61$ neutrophils $/ \mathrm{mm}^{2}$ were either rolling or stationary on the luminal surface, $n=16$; on IL- $1 \beta$-stimulated HUVEC monolayers, $657 \pm 55$ neutrophils $/ \mathrm{mm}^{2}$ were counted, $n=16$. Monolayers of the parent L-cells showed extremely low adhesiveness for unstimulated or stimulated neutrophils ( $5.4 \pm 1.3$ neutrophils/ $\mathrm{mm}^{2}$ were associated with the monolayer; $n=10$ ). Pretreatment of L-ELAM cell monolayers with anti-E-selectin mAb almost completely blocked adhesion (Fig. $1 \mathrm{~A}$ ), indicating that the interactions of neutrophils with these cells is essentially


Figure 1. Adhesion of neutrophils to L-ELAM cell monolayers under conditions of flow. $(A)$ Confluent monolayers of L-ELAM cells were assembled onto parallel plate flow chambers, rinsed for 10 min with M199 at a wall shear stress of $1.85 \mathrm{dyn} / \mathrm{cm}^{2}$, and perfused for 10 min with neutrophil suspensions in the presence of mAbs. Neutrophils associated with the monolayers (per $\mathrm{mm}^{2}$ ) were determined by digital analysis of video tapes of each experiment. Monolayers were incubated with anti-E-selectin $\mathrm{mAb}$ for $30 \mathrm{~min}$ before assembly onto the flow chamber. Anti-E-selectin mAb was maintained in the rinse media and cell suspension. Neutrophils $\left(10^{6} \mathrm{cells} / \mathrm{ml}\right)$ were incubated with anti-L-selectin $\mathrm{mAb}$ for $15 \mathrm{~min}$ at room temperature. Neutrophil activation was accomplished by incubation with $10 \mathrm{nM}$ FMLP at room temperature for 25 min, at which time activated neutrophils were either diluted to $1 \mathrm{nM}$ with M199 and perfused through the flow chamber (FMLP) or washed twice with PBS and resuspended in RPMI-1640 for 5-10 min before perfusion through the flow chamber $(F M L P$-Washed $) .{ }^{*} P<0.01$ as compared with control neutrophils and ${ }^{\ddagger} P<0.01$ as compared to activated neutrophils. Number of separate determinations in parenthesis. $(B)$ Photograph of adhesion and rolling of isolated neutrophils to L-ELAM cell monolayer under conditions of flow as described in $A$ above. In contrast to neutrophil-endothelial cell interactions, neutrophils adherent on the surface of the L-ELAM cell monolayers remained spherical and either rolled or remained stationary on the luminal surface of the monolayer. Images are presented from top to bottom and are $20 \mathrm{~s}$ apart. The direction of flow is from left to right. 
E-selectin dependent. Few neutrophils associated with human ICAM-1-transfected L cell monolayers (L-ICAM-1) at this wall shear stress ( 20.2 neutrophils $/ \mathrm{mm}^{2}$ were counted, $n=2$ ). Expression levels of ICAM-1 in L-ICAM cell monolayers were similar to that of the IL-1-stimulated $(3 \mathrm{~h})$ HUVEC monolayers (optical density values \pm SD: HUVEC, 1.694 \pm 0.140 ; LICAM, $1.594 \pm 0.152, n=5$ ).

E-selectin has been shown to recognize sLe $\mathrm{s}^{\mathrm{x}}$, an abundant carbohydrate residue on the neutrophil surface $(35,36)$. Preincubation of neutrophils with neuraminidase causes enzymatic cleavage of the sialic acid residues from the neutrophil surface, without activating the cells as indicated by the finding that surface levels of L-selectin on these cells were not changed ( Table I). Adhesion of neuraminidase-treated neutrophils to LELAM cell monolayers was found to be diminished by $73.2 \pm 9.9 \%(n=5, P<0.01)$ compared to control neutrophils exposed to all steps of neuraminidase treatment without exposure to the enzyme.

Adhesion of isolated neutrophils to L-ELAM monolayers involved rolling and stopping (Fig. $1 B$ ). The neutrophil populations identified in this system included $(a)$ neutrophils rolling on the luminal surface, $(b)$ neutrophils attached and stationary on the luminal surface, and $(c)$ neutrophils passing through the chamber without contacting the monolayer. These three populations were in dynamic exchange. As new neutrophils adhered to the monolayer, some would roll and move downstream with the flow, and others would stop at the point of adhesion or shortly thereafter; stationary neutrophils would suddenly roll and rolling neutrophils would stop. At times, stationary or rolling neutrophils would detach from the monolayer and move away with the flowing fluid. The total number of adherent neutrophils was evaluated as the sum of the rolling and stationary cells and comprised $<1 \%$ of the neutrophils which passed through the chamber.

\section{E-selectin supports neutrophil rolling under conditions of flow}

In six experiments analyzed for the rolling phenomenon over a 1-5-s time frame, $47.8 \pm 6.0 \%$ of the adherent neutrophils were rolling (Fig. 2, $A$ and $B$ ). The average velocity of rolling for the rolling population was $10.6 \pm 1.7 \mu \mathrm{m} / \mathrm{s}$, and under phase-contrast optics, these cells resembled solid translucent spheres rolling on the luminal surface of the monolayer. As these spheres were turning, the internal granules would transiently come to

Table I. Effect of Neuraminidase Treatment on Neutrophil L-Selectin and $s L e^{x}$

\begin{tabular}{lccc}
\hline $\begin{array}{c}\text { Monoclonal } \\
\text { antibody }\end{array}$ & $\begin{array}{c}\text { Control } \\
\text { neutrophils }\end{array}$ & $\begin{array}{c}\text { Neuraminidase-treated } \\
\text { neutrophils }\end{array}$ & $\begin{array}{c}\text { Percent } \\
\text { reduction }\end{array}$ \\
\hline & & & $\%$ \\
Anti-L-selectin & $416 \pm 47$ & $443 \pm 55$ & $-5 \pm 3$ \\
Anti-sLe & $2805 \pm 519$ & $62 \pm 12$ & $97 \pm 1$ \\
\hline
\end{tabular}

Neuraminidase treatment of isolated neutrophils. Isolated adult neutrophils were incubated with $0.1 \mathrm{U} / \mathrm{ml}$ neuraminidase at room temperature and $10^{7}$ cells $/ \mathrm{ml}$ for $30 \mathrm{~min}$, then washed, and resuspended at $10^{7} \mathrm{cell} / \mathrm{ml}$. The effect of this treatment on L-selectin and sLe ${ }^{\mathrm{x}}$ expression levels was measured by flow cytometry techniques employing mAbs directed against these adhesion molecules. Mean fluorescence values \pm 1 SD for seven separate experiments are given. the plane of focus. The magnitude of the E-selectin-dependent adhesive interactions between the rolling leukocytes and LELAM cell monolayers is evident when compared with the calculated rolling velocity of a solid noninteracting sphere of 8 $\mu \mathrm{m}$ in diameter rolling on a plane surface (Fig. $2 C$ ). Assumptions included no slippage between the sphere and the planar surface and no slippage between the sphere and the laminar flow stream immediately above it, which would make the axial velocity equal to the laminar flow stream at $8 \mu \mathrm{m}$ from the coverglass surface. Because the Reynolds number was $<4$, we used the analytical solution for fluid velocity in a rectangular geometry with half-channel height of $1.016 \times 10^{-4} \mathrm{~m}$, channel width of $3.175 \times 10^{-3} \mathrm{~m}$, flow rate of $1.154 \times 10^{-8} \mathrm{~m}^{3} / \mathrm{s}$, and viscosity of 0.007 poise at $37^{\circ} \mathrm{C}$ and calculated a velocity of $2068 \mu \mathrm{m} / \mathrm{s}$ for the center of the noninteracting rolling sphere.

The rolling phenomenon did not appear to be simply a physical event which would occur in the absence of E-selectindependent interactions of neutrophils with L-ELAM monolayers. The adhesive interactions must be of sufficient strength to withstand the drag force generated by the flowing fluid. Efforts to measure the velocity of rolling of spherical glass beads of $10.3 \mu \mathrm{m}$ in diameter in the flow chamber clearly illustrated this point. At a wall shear stress of $1.85 \mathrm{dyn} / \mathrm{cm}^{2}$ the glass beads did not roll but flowed in a narrow region close to the midline of the chamber. The wall shear stress had to be reduced to 0.02 $\mathrm{dyn} / \mathrm{cm}^{2}$ before glass beads were moving slow enough to be captured by the camera. The average flowing velocity of these particles was $102.2 \pm 4.3 \mu \mathrm{m} / \mathrm{s}$. This observation was in agreement with experiments using parent L-cells, L-ICAM cells, or unstimulated HUVEC monolayers where flowing neutrophils would pass over the monolayer at high velocities without significant contacting of the luminal surface.

\section{E-selectin-dependent neutrophil adhesion to endothelial monolayers}

Although the results presented above are consistent with the idea that the E-selectin alone can support neutrophil adhesion under flow, it is not known whether E-selectin does so in the complex environment of the activated endothelial cell. We have shown previously that rolling adhesion of neutrophils occurs on IL-1 $\beta$ - or LPS-stimulated endothelial cell monolayers, but a high percentage of this adhesion is apparently L-selectin dependent $(12,13)$. Anti-E-selectin pretreatment of the HUVEC monolayer caused a moderate but significant reduction in adhesion (Fig. $3 \mathrm{~A}$ ). This inhibition was much lower than that observed on L-ELAM cell monolayers where adhesion was almost completely E-selectin dependent. H18/7 a second antiE-selectin mAb, provided by Dr. M. A. Gimbrone of Harvard Medical School, Boston, MA, resulted in a similar reduction in adhesion (adhesion to CL2/ $6 \mathrm{~F}\left(\mathrm{ab}^{\prime}\right)_{2}$-treated endothelial cell monolayers was $67.8 \%$ of control, $n=14$, and adhesion to $\mathrm{H} 18 / 7 \mathrm{~F}\left(\mathrm{ab}^{\prime}\right)_{2}$-treated monolayers was $69.4 \%$ of control, $n$ $=2$ ). Pretreatment of neutrophils with anti-L-selectin caused a more substantial reduction in adhesion than anti-E-selectin $(P<0.01$ unpaired two tailed $t$-test against anti-E-selectin percent inhibition) (Fig. $3 A$ ). Adhesion was not reduced further when anti-L-selectin-treated neutrophils were allowed to contact anti-E-selectin-treated endothelial cell monolayers.

Adherent neutrophils on HUVEC monolayers were either rolling or stationary and, as seen with L-ELAM cells, these two populations of leukocytes were in active exchange with the flowing population. However, an important difference was 

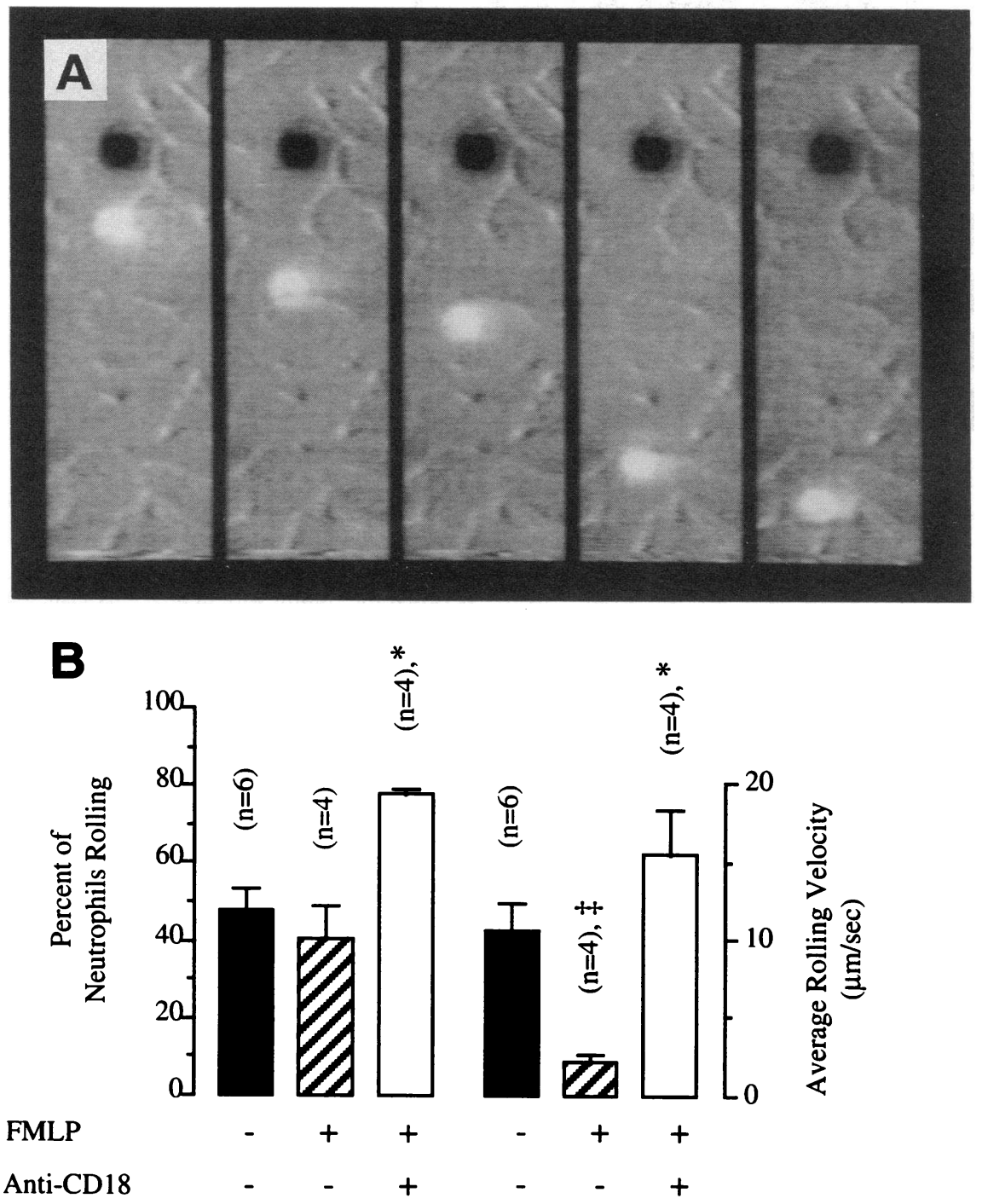

C

Center of the chamber

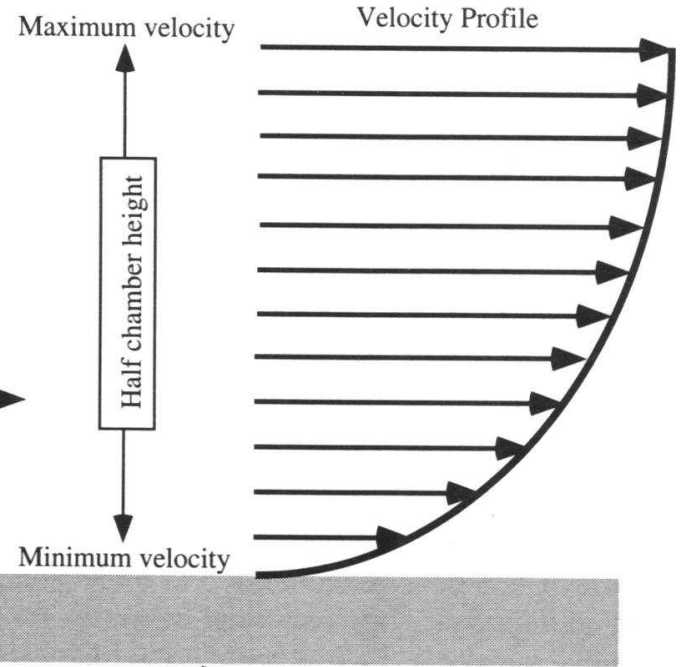

Figure 2. Rolling velocity of isolated human neutrophils on L-ELAM monolayers at a wall shear stress of $1.85 \mathrm{dyn} / \mathrm{cm}^{2}$. Experiments were performed as described in Fig. 1. $(A)$ Two frames, from video recordings of each experiment, were digitized. The second frame was then subtracted from the first one to yield a background subtracted image, where the dark spots represent the original position of the cell and the bright spots indicate the new location of the cell at times 1-5 $s$ later. The set of subtracted images shown in this photograph were acquired at time intervals of $1,2,3,4$, and 5 and are arranged from left to right with the cells flowing downward. The distance between these locations was then calculated and divided by the time interval between the two frames to give the rolling velocity in $\mu \mathrm{m} / \mathrm{s}$. The minimum and maximum rolling velocities measured were 0.2 and $84 \mu \mathrm{m} / \mathrm{s}$. (B) The ratio of rolling population of neutrophils (measured as explained in $A$ ) to total neutrophils associated with the monolayer (sum of the rolling and stationary populations as measured in Fig. 1) was used to calculate the percent rolling and is compared with the average velocity of these cells. Experiments were performed with control neutrophils, activated neutrophils $(F M L P+)$, anti-CD18-treated activated

In absence of slippage between top of the cell and the flow stream at that height, the cells would roll with a radial velocity equal to the velocity of the flow stream at their apex.

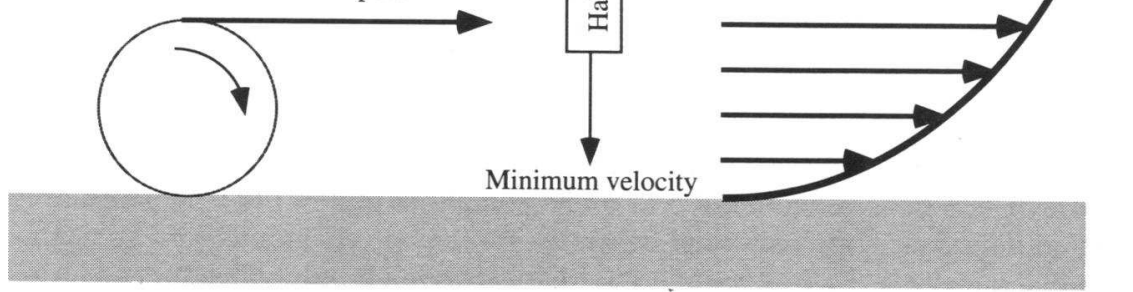
neutrophils (FMLP+, Anti-CD18+) as described in Fig. 1. (C) Schematic diagram of the rolling noninteracting sphere. A hard sphere of $8 \mu \mathrm{m}$ in diameter was used in calculation of the rolling velocity with the assumptions of no slippage between the top of the sphere and the flow stream at that height and no slippage between the sphere and the coverglass. ${ }^{*} P<0.05$ as compared with control and chemotactic stimulation; ${ }^{\ddagger} P<0.05$ as compared with control.

found. Most stationary neutrophils on HUVEC monolayer became activated, exhibiting shape change and transendothelial migration $(12,13,18)$ (Fig. $3 B$ ). Though anti-E-selectin mAb significantly reduced the number of transmigrated neutrophils as did anti-L-selectin mAb $(12,14)$, it did not influence the percent of the adherent cells that transmigrated. Anti-E-selec- 
Treatment
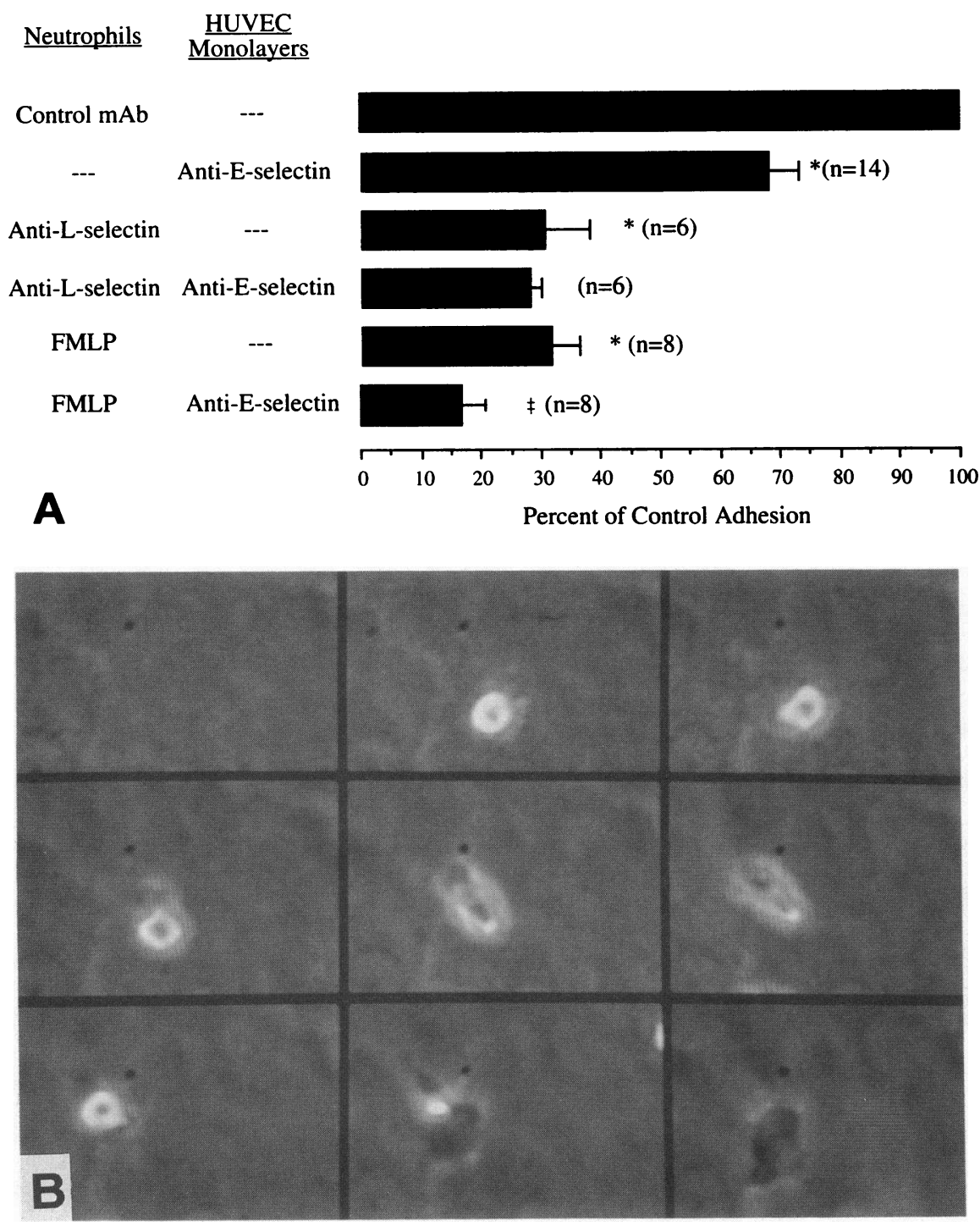

Figure 3. Adhesion of isolated adult neutrophils to HUVEC monolayers at the wall shear stress of $1.85 \mathrm{dyn} / \mathrm{cm}^{2}$. (A) Confluent HUVEC monolayers were stimulated with IL- $1 \beta$ at $5 \mathrm{U} / \mathrm{ml}$ for $3 \mathrm{~h}$ in tissue culture incubator, then assembled onto parallel plate flow chambers, rinsed for 10 min with M199 at a wall shear stress of $1.85 \mathrm{dyn} / \mathrm{cm}^{2}$, and perfused for $10 \mathrm{~min}$ with neutrophils suspensions $\left(10^{6}\right.$ cells $\left./ \mathrm{ml}\right)$ in presence or absence of mAbs. Adherent neutrophils per $\mathrm{mm}^{2}$ were determined by digital analysis of video tapes of each experiment. Monolayers were incubated with anti-E-selectin $\mathrm{mAb}$ for 30 $\min , 37^{\circ} \mathrm{C}$, before assembly onto the flow chamber. Anti-E-selectin mAb was maintained in the rinse media and cell suspensions. Neutrophils $\left(10^{7}\right.$ cells $\left./ \mathrm{ml}\right)$ were incubated with anti-L-selectin mAb for 15 min at room temperature. Neutrophil activation was accomplished by incubation with $10 \mathrm{nM}$ FMLP at room temperature for $15 \mathrm{~min} .{ }^{*} P$ $<0.01$ as compared with control neutrophils; ${ }^{\ddagger} P<0.01$ as compared to activated neutrophils. Number of separate determinations in parentheses. ( $B$ ) Photomicrographs of neutrophil-endothelial cell interactions. Images are $40 \mathrm{~s}$ apart and show the adhesion, activation, and transmigration of adherent neutrophils to activated endothelial cells and are arranged from left to right starting from top row. tin apparently reduced the number of extravasated neutrophils simply by reducing the number of adherent cells on the luminal surface (Fig. 4). In contrast, anti-CD18 and antiICAM-1 mAbs have been shown to reduce the percentage of the adherent cells transmigrated by blocking transendothelial migration without influencing the quantity of the neutrophils adherent on the luminal surface of the endothelium $(12,13$, $18,34)$.

\section{Possible neutrophil determinants of E-selectin-dependent adhesion under conditions of flow}

Effects of anti-L-selectin $m A b$. Kishimoto et al. (29) and Picker et al. (32) have provided evidence for participation of E-selectin and neutrophil L-selectin in a common adhesion under static conditions. We have recently shown that a major component of neutrophil-endothelial cell adhesion under conditions of flow (wall shear stress of $1.85 \mathrm{dyn} / \mathrm{cm}^{2}$ ) is supported by a L-selectin-dependent mechanism $(12,13)$. We, therefore, assessed the possible contribution of L-selectin under experi- mental settings where adhesion is primarily E-selectin dependent. Pretreatment of isolated neutrophils with anti-L-selectin mAb (DREG-56) markedly inhibited adhesion to L-ELAM monolayers under conditions of flow (Fig. $1 A$ ). Incubation of neutrophils with anti-L-selectin at $37^{\circ} \mathrm{C}$ did not appear to activate the cells since it did not elicit shape change, loss of L-selectin from cell surface, upregulation of CD1 1b/CD18, change in light scatter in flow cytometry, $\mathrm{Ca}^{++}$flux in fura-2-loaded cells or chemiluminescence after cross-linking of DREG-56 (data not shown).

Adhesion of neonatal neutrophils. We have recently found that neonatal neutrophils have reduced adhesion to activated endothelial cells under conditions of flow (14). Neonatal cells adhered and rolled on E-selectin cell monolayers at significantly lower levels than paired adult cells with adhesion levels of $52.8 \pm 5.5 \%$ of the adult neutrophils $(P<0.001$, Fig. $5 A)$, and the adhesion of neonatal neutrophils was significantly correlated with their surface levels of L-selectin (37). L-selectin on neonatal and healthy adult neutrophils was assessed using 


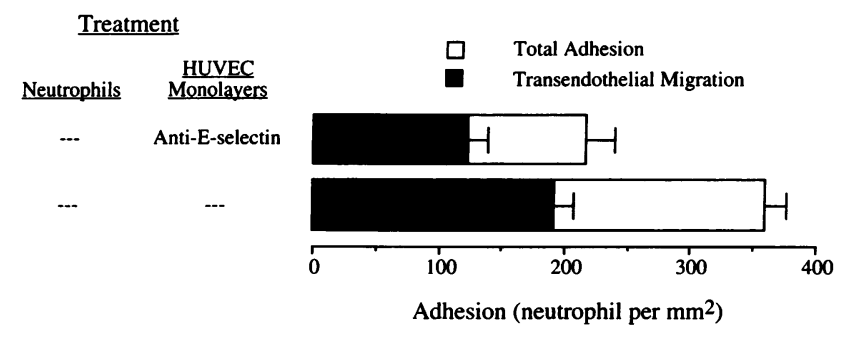

Treatment

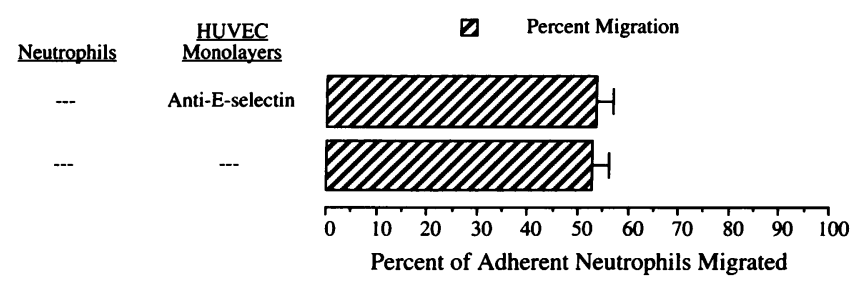

Figure 4. Transendothelial migration of isolated neutrophils under conditions of flow. Endothelial cell monolayers were stimulated with IL- $1 \beta(5 \mathrm{U} / \mathrm{ml}, 3 \mathrm{~h})$, placed in parallel plate flow chamber, rinsed with M199 at a wall shear stress of $1.85 \mathrm{dyn} / \mathrm{cm}^{2}$, and perfused for $10 \mathrm{~min}$ with neutrophils suspensions in the presence of $\mathrm{mAb}$ when indicated. Adherent and transmigrated neutrophils were determined by analysis of video tapes of each experiments. Monolayers were incubated with anti-E-selectin $\mathrm{mAb}$ for $30 \mathrm{~min}$ in tissue culture incubator before assembly onto the flow chamber. Anti-E-selectin $\mathrm{mAb}$ was maintained in the rinse media and cell suspension $(n=14)$.

flow cytometry. A highly significant correlation was obtained when adhesion to L-ELAM monolayers was plotted against anti-L-selectin binding (Fig. $5 \mathrm{~B}$ ).

In a second set of experiments comparing the neonatal and adult neutrophils, neuraminidase treatment of the neutrophils resulted in marked reduction in adhesion to L-ELAM monolayers (Fig. 6) without affecting the surface level of neutrophil L-selectin. While these results are consistent with the interpretation that $\mathrm{sLe}^{\mathrm{x}}$ is necessary for adhesion of neutrophils to E-selectin under conditions of the flow, additional observations indicate that most surface $\mathrm{sLe}^{\mathrm{x}}$ may not be involved. Fig. 7 shows a plot of CSLEX (anti-sLe ${ }^{x}$ ) binding to neutrophils against adhesion under flow. The correlation is weaker than that seen between anti-L-selectin binding and adhesion (Fig. $5 B$ ).

Effects of chemokinetic stimulation of neutrophils. We have previously shown that chemotactic stimulation of neutrophils reduces neutrophil adhesion to cytokine-stimulated endothelial cell monolayers under conditions of flow. As shown in Fig. $1 A$, this is also true for adult neutrophils on L-ELAM monolayers. After incubation with chemotactic peptide FMLP ( 10 $\mathrm{nM}$ ) for $25 \mathrm{~min}$ (13), the concentration of FMLP was reduced either by diluting it to $1 \mathrm{nM}$ or by washing the cells to reduce FMLP to very low concentrations. This drop in the chemotactic stimulus resulted in the activated neutrophils changing from a bipolar shape to a spherical shape capable of rolling on monolayers. Under these conditions adhesion under flow was reduced by $\sim 60 \%$. The residual adhesion that occurred (Fig. 1 $A$ ) was not dependent on CD18-antigens since pretreatment of these neutrophils with anti-CD18 did not further reduce the adhesion. However, anti-E-selectin significantly reduced the adhesion of FMLP-stimulated cells. Thus, the surface receptors which mediated adhesion of activated neutrophils to L-ELAM cell monolayers were apparently different from CD18-integrins or L-selectin ( since L-selectin is shed from the neutrophil surface).

Fig. $8 \mathrm{~A}$ shows additional experiments on the effect of chemotactic stimulation on adhesion to L-ELAM cell monolayers
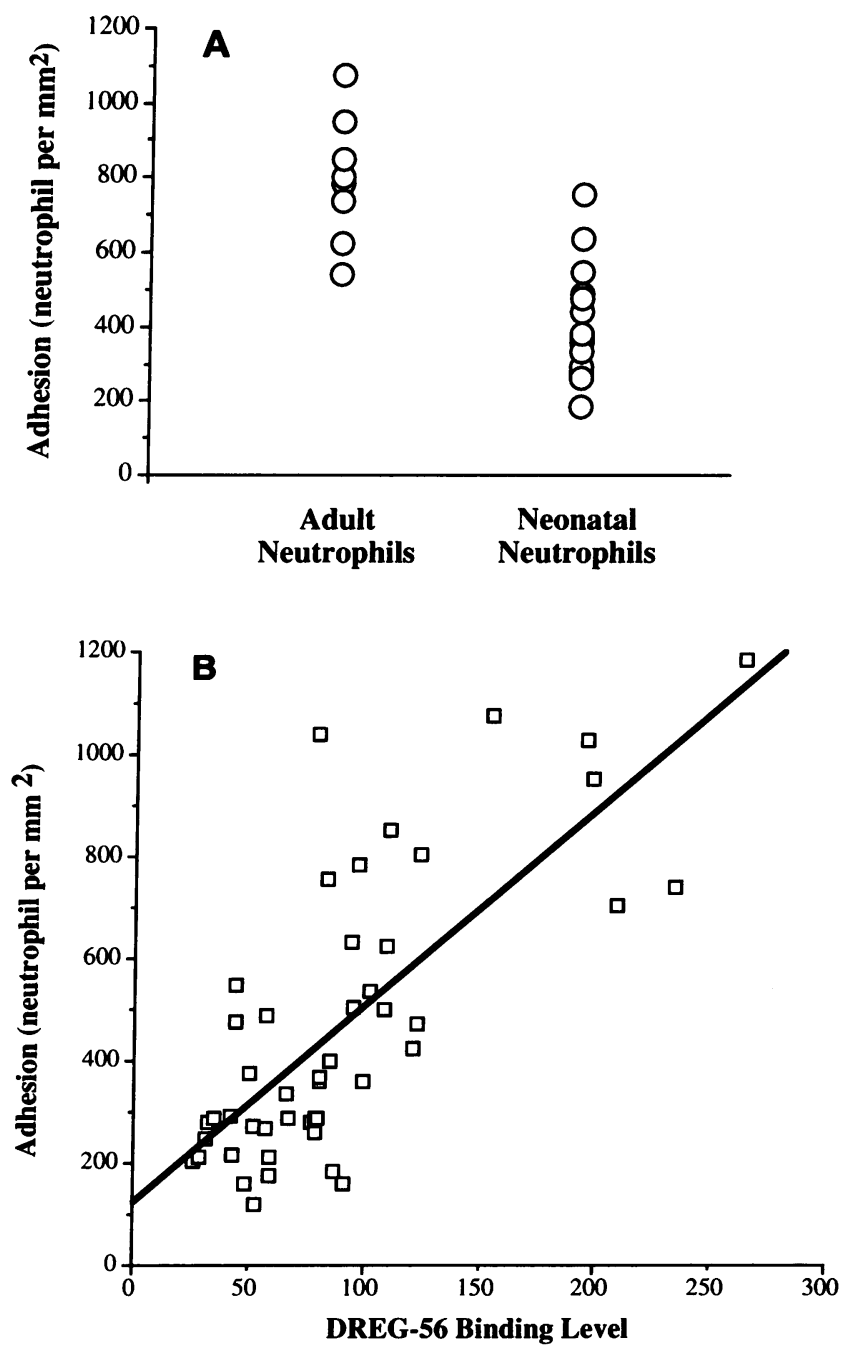

Figure 5. Adhesion of neonatal and adult neutrophils to L-ELAM cell monolayers under conditions of flow. Confluent monolayers of LELAM cells were assembled onto parallel plate flow chambers, rinsed for $10 \mathrm{~min}$ with M199 at a wall shear stress of $1.85 \mathrm{dyn} / \mathrm{cm}^{2}$, and perfused for $10 \mathrm{~min}$ with neutrophil suspensions. Neutrophils associated with the monolayer ( per $\mathrm{mm}^{2}$ ) were determined by digital analysis of video tapes of each experiment. $(A)$ Comparison of the adhesion level of neonatal neutrophils with that of the adult neutrophils. Neonatal cells adhered at $52.8 \pm 5.5 \%$ of the paired adult neutrophils $(P<0.001)$. ( $B)$ Adhesion of neonatal and adult neutrophils as a function of L-selectin expression. L-selectin expression was assessed by anti-L-selectin mAb (DREG-56) binding levels using flow cytometric techniques. Anti-L-selectin binding is expressed in units of fluorescence. A significant correlation exists between adhesion and L-selectin expression of neutrophils with coefficient of correlation of 0.742 and $P<0.001$. 
$\mathbf{A}$

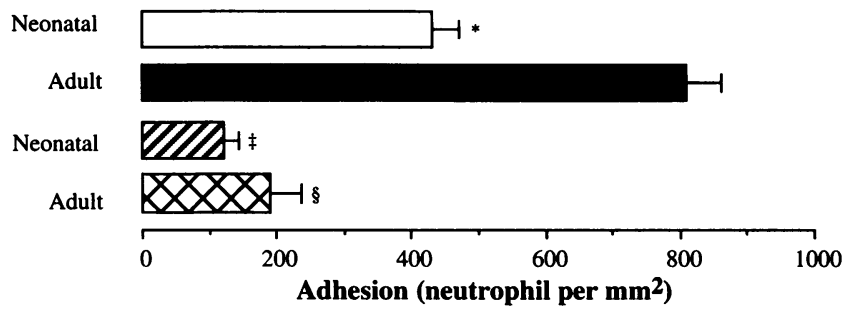

B

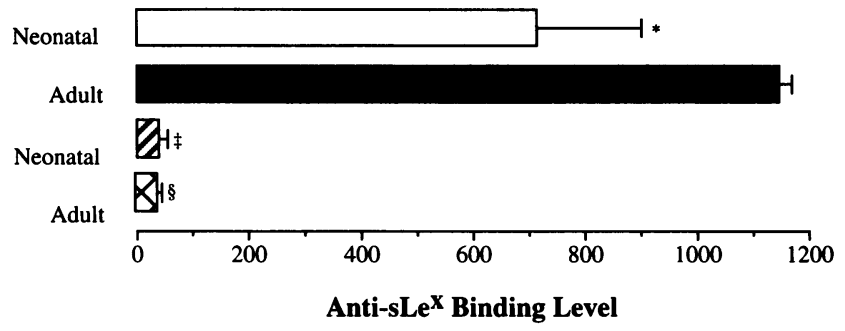

C

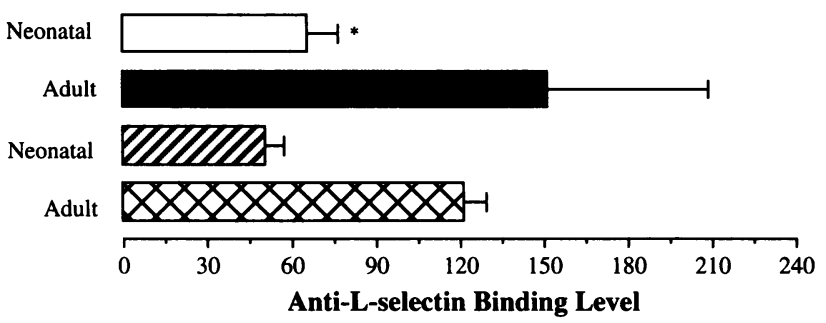

Figure 6. Effect of neuraminidase treatment of isolated neonatal and adult neutrophils on adhesion to L-ELAM monolayers under wall shear stress of $1.85 \mathrm{dyn} / \mathrm{cm}^{2}(A)$, and $\mathrm{sLe}^{\mathrm{x}}(B)$, and L-selectin $(C)$ cell surface levels. $(A)$ Isolated neutrophils were perfused through the flow chamber as described in Fig. 1. Neuraminidase treatment was accomplished by incubation of the isolated neutrophils $\left(10^{7}\right.$ cells $\left./ \mathrm{ml}\right)$ with neuraminidase at $0.1 \mathrm{U} / \mathrm{ml}$ for $30 \mathrm{~min}$ at room temperature at which time the cells were washed with PBS and resuspended in PBS at $10^{7}$ cells $/ \mathrm{ml}$ and stored at $4^{\circ} \mathrm{C}$. Control cells for these experiments were also stored at room temperature for $30 \mathrm{~min}$ and washed with PBS. ( $B$ and $C$ ) $\mathrm{sLe}^{\mathrm{x}}$ and $\mathrm{L}$-selectin expression levels of these cells were accomplished using flow cytometric analysis techniques of antisLe $^{x}$ and anti-L-selectin binding intensity to washed and neuraminidase-treated neonatal and adult neutrophils and are expressed in units of fluorescence. Open bars, neonatal neutrophils; solid bars, adult neutrophils; hatched bars, FMLP-activated neonatal neutrophils; and crosshatched bars, FMLP-activated adult neutrophils. ${ }^{*} P<0.01$ as compared to paired adult adhesion; ${ }^{\ddagger}$ as compared to unstimulated neonatal adhesion, and ${ }^{\S}$ as compared to unstimulated adult adhesion.

where adult and neonatal neutrophils were compared. Neonatal cells again adhered at much lower levels than the adult cells before activation $(P<0.01)$. Chemotactic activation brought adhesion of both adult and neonatal neutrophils to the same low level which was significantly below their corresponding prestimulated values $(P<0.01)$. L-selectin surface levels were also significantly reduced following activation (Fig. $8 \mathrm{~B}$ ). However, chemotactic stimulation under conditions shown to significantly reduce L-selectin levels and adhesion (Figs. $1 A$ and 8), did not significantly reduce CSLEX (anti-sLe ${ }^{\mathbf{x}}$ ) binding.

Effects of chemotactic stimulation on neutrophil rolling. In addition to the fact that neutrophil stimulation leads to a marked reduction in the number of cells adherent to L-ELAM cell monolayers (Fig. $1 A$ ), we observed a reduction in the average velocity of rolling to $2.2 \pm 0.6 \mu \mathrm{m} / \mathrm{s}(P<0.05$ compared to the velocity of rolling of control cells) without affecting the ratio of the rolling cells to adherent cells (Fig. $2 B$ ). To address the question whether this lower velocity was due to upregulation of the CD18-integrins, the effects of preincubating activated neutrophils with mAb R15.7 (anti-CD18) was measured. The anti-CD18-treated, activated neutrophils had a rolling velocity of $15.4 \pm 3.0 \mu \mathrm{m} / \mathrm{s}$, which is significantly higher than that of the control or activated leukocytes. In addition, there was an increase in the ratio of the rolling cells to adherent cells which was also statistically significant when compared with control or activated cells. As noted above, anti-CD18 pretreatment of the activated neutrophils did not influence the number of neutrophils associating with the L-ELAM monolayers (Fig. $1 A$ ). These observations are consistent with our previously reported data showing rolling velocities on IL-1-stimulated HUVEC monolayers were significantly lower for activated neutrophils $(12,38)$, while those for CD18-deficient neutrophils were significantly elevated (12).

The ligand recognized by $\mathrm{CD} 18$ intergrins on the $\mathrm{L}$ cell monolayer is not known. We were unable to detect murine ICAM-1 on these cells by ELISA using mAb YN1 / 1.7 (antimurine ICAM-1), a result consistent with earlier studies (29), but in experiments without shear stress, FMLP-stimulated neutrophils were consistently more adherent to L cell monolayers than unstimulated neutrophils (unstimulated neutrophils,

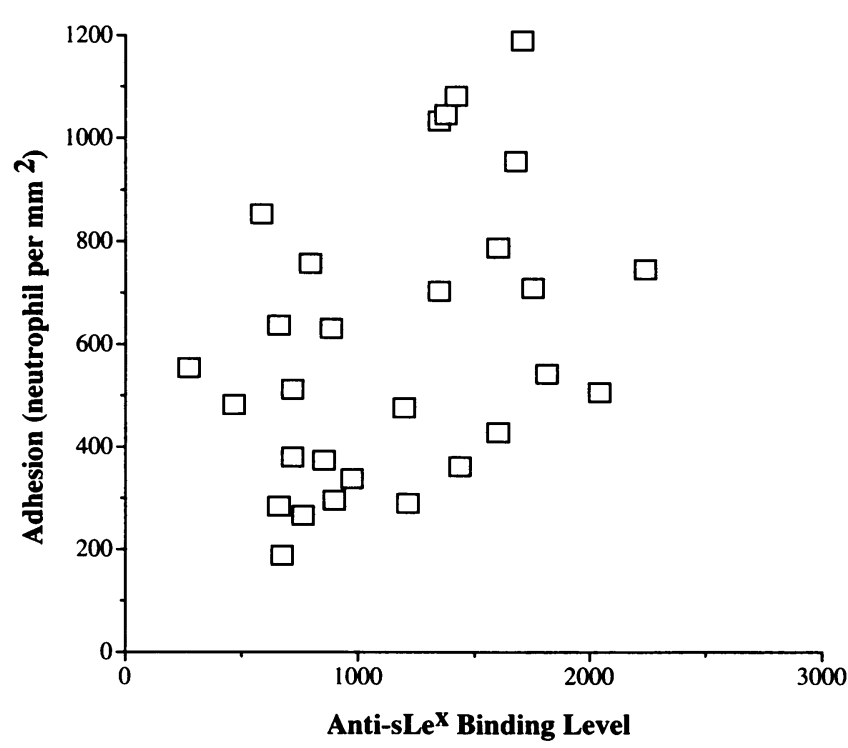

Figure 7. Adhesion of neonatal and adult neutrophils to L-ELAM cell monolayers at the wall shear stress of $1.85 \mathrm{dyn} / \mathrm{cm}^{2}$ as a function of sLe $^{x}$ expression. Confluent monolayers of L-ELAM cells were assembled onto parallel plate flow chamber, rinsed for 10 min with M199 at a wall shear stress of $1.85 \mathrm{dyn} / \mathrm{cm}^{2}$, and perfused for $10 \mathrm{~min}$ with neutrophil suspension in M199 ( $10^{6}$ cells/ml). Adherent neutrophils per $\mathrm{mm}^{2}$ were determined by digital analysis of video tapes of each experiment. $s L e^{x}$ expression was assessed by anti-sLe ${ }^{x} \mathrm{mAb}$ binding levels using flow cytometric techniques and is expressed in units of fluorescence. Some correlation apparently exists between adhesion and $\mathrm{sLe}^{\mathrm{x}}$ cell surface levels of neutrophils with coefficient of correlation of 0.408 and $P<0.05$. 
A

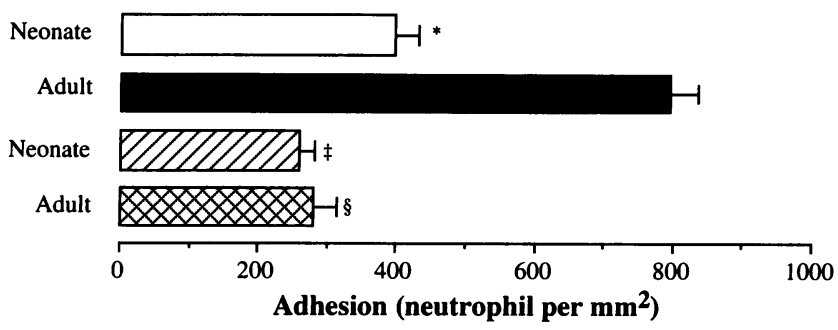

B

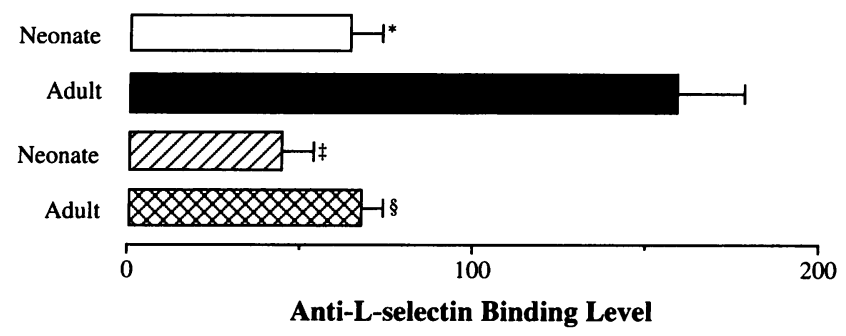

Figure 8. Effect of chemotactic stimulation of isolated neonatal and adult neutrophils on $(A)$ adhesion to L-ELAM monolayers under conditions of flow and $(B) \mathrm{L}$-selectin cell surface levels. $(A)$ Isolated neutrophils were perfused through the flow chamber as described in Fig. 1. Neutrophil activation was accomplished by incubation with $10 \mathrm{nM}$ FMLP at room temperature for $15 \mathrm{~min}$. Activated neutrophils were diluted with $\mathrm{M} 199\left(37^{\circ} \mathrm{C}\right.$, and $\left.\mathrm{pH} 7.4\right)$ to $10^{6}$ cell $/ \mathrm{ml}$ concentration ( $1 \mathrm{nM}$ FMLP) and perfused through the flow chambers for $10 \mathrm{~min}$. The 10 -fold reduction in FMLP concentration caused neutrophils to revert to a spherical configuration. $(B)$ L-selectin expression levels were assessed via flow cytometric analysis of the binding of anti-L-selectin mAb (DREG-56, in fluorescence unit) to control and activated neutrophils. Open bars, neonatal neutrophils; solid bars, adult neutrophils; hatched bars, FMLP activated neonatal neutrophils; and crosshatched bars, FMLP activated adult neutrophils. ${ }^{*} P<0.01$ as compared to paired adult adhesion; ${ }^{\star}$ as compared to unstimulated neonatal adhesion, and ${ }^{\S}$ as compared to unstimulated adult adhesion.

$4 \pm 2 \%$ adhesion; FMLP, $10 \mathrm{nM} ; 19 \pm 3 \%, n=4, P<0.01)$ a finding that is consistent with the interpretation that some murine cell surface component is recognized by CD18-integrins. $\mathrm{CD} 1 \mathrm{~b} / \mathrm{CD} 18$ has been found to bind to a wide array of apparently unrelated proteins, and its avidity is enhanced by chemotactic stimulation (39).

\section{Discussion}

In this report we have shown that E-selectin expressed on a cell monolayer can support neutrophil rolling under conditions of flow with wall shear stresses that preclude ICAM-1-dependent adhesion. This conclusion is primarily based on the observation that isolated human neutrophils adhered and rolled on human E-selectin-transfected murine $\mathrm{L}$ cell monolayers at a wall shear stress of $1.85 \mathrm{dyn} / \mathrm{cm}^{2}$, but failed to interact with ICAM-1-transfected L cells at the same wall shear stress, even though ICAM-1 expressing L cells has been shown to support activated neutrophil adhesion under static conditions (40). These observations serve to point out the possible significance of fluid flow forces on the relative contribution of these two adhesion molecules in the interaction of neutrophils with endo- thelial cell monolayers. Endothelial cells simultaneously express on their apical surface both E-selectin and ICAM-1 in the first few hours after stimulation with TNF $\alpha$, IL-1 $\beta$, or LPS (34, 40, 41). Under static conditions, both endothelial E-selectin and ICAM-1 support neutrophil adhesion equally well, but under flow at physiologic shear stresses, ICAM-1 seems unable to catch neutrophils. Lawrence et al. (18) and Smith et al. (34) found that mAb R6.5 (anti-ICAM-1) was without effect on adhesion of neutrophils to IL- $\beta$-stimulated endothelial monolayers at a wall shear stress of $2.0 \mathrm{dyn} / \mathrm{cm}^{2}$, and purified ICAM-1 in a planar membrane did not support rolling at this flow rate (42).

While these results indicate that E-selectin is capable of supporting neutrophil adhesion under flow, they do not show that E-selectin serves this function when expressed on endothelial cells. In this regard, there were some potentially important differences in experimental results between the condition with artificial presentation of E-selectin on $\mathrm{L}$ cell monolayers, and the results with cytokine-stimulated endothelial cell monolayers. The first was that while anti-E-selectin precluded adhesion to L-ELAM, anti-E-selectin mAbs diminished neutrophil adhesion to IL- $1 \beta$-stimulated endothelial cell monolayers by only $\simeq 30 \%$. This finding contrasts to the results with anti-Lselectin $\mathrm{mAb}$, where inhibition is consistently $>60 \%$ in studies with both human $(13,14)$ and canine cells (12). Our current studies indicate that, while endothelial E-selectin is involved, the interaction between neutrophils and stimulated endothelial cells occurring at physiologic wall shear stresses is more complex than could be predicted by the results with L-ELAM cell monolayers.

Another important difference between the results on LELAM and activated HUVEC was the finding that though rolling was the initial behavior of adherent neutrophils in both settings, leukocytes on L-ELAM monolayers retained a spherical shape and rolled with only transient stopping, while leukocytes on endothelial cells most often stopped after rolling, changed shape, and a high percentage migrated beneath the monolayer. This difference suggests that though E-selectin expressed on the apical surface of a cell monolayer may be able to initiate neutrophil adhesion under flow, it is insufficient to activate the behaviors neutrophils need for diapedesis. While some apparent contradictions exist in the literature regarding the role of E-selectin in transendothelial migration of neutrophils (29, 43-46 ), our experiments fail to provide any evidence that E-selectin is directly involved.

Given the results in the present report, it is now clear that each member of the selectin family is capable of supporting neutrophil rolling, a phenomenon that has been known for many years to occur in venules at inflammatory sites. Neutrophils roll in vitro on isolated P-selectin in an artificial planar membrane (42) at 5-10 $\mu \mathrm{m} / \mathrm{s}$ when the wall shear stress is 1.8 $\mathrm{dyn} / \mathrm{cm}^{2}$, and on L-ELAM cell monolayers at $\simeq 10 \mu \mathrm{m} / \mathrm{s}$ when the wall shear stress of $1.85 \mathrm{dyn} / \mathrm{cm}^{2}$. On IL- $1 \beta-$ stimulated HUVEC monolayers, isolated neutrophils roll at $\simeq 10 \mu \mathrm{m} / \mathrm{s}$ when the wall shear stress is $\simeq 2 \mathrm{dyn} / \mathrm{cm}^{2}$. The need for an adhesive mechanism initiating the rolling attachment is clearly shown by the observations with flowing glass beads where rolling did not occur even at the very low shear stress of $0.02 \mathrm{dyn} / \mathrm{cm}^{2}$. E-selectin-dependent rolling was particularly evident in adhesion to L-ELAM monolayers where a high percentage of cells was rolling during the 1-5-s analysis 
periods. Comparing the calculated velocity of a rolling noninteracting sphere at a wall shear stress of $1.85 \mathrm{dyn} / \mathrm{cm}^{2}(\simeq 2,000$ $\mu \mathrm{m} / \mathrm{s})$ and the measured velocity of rolling neutrophils on $\mathrm{L}$ ELAM monolayers $(\simeq 10 \mu \mathrm{m} / \mathrm{s})$ demonstrates the contribution of the E-selectin-dependent pathway in resisting the forces generated by the flowing fluid. An additional contribution to the adhesive interaction between neutrophils and L-ELAM monolayers occurred when neutrophils were stimulated with a chemotactic factor prior to passing them over the L-ELAM monolayer. Though this stimulation greatly reduced the number of leukocytes interacting with the monolayer, the rolling velocity of those that did interact was significantly reduced. The diminished velocity was most likely coupled to upregulated CD18 integrin function since the effect of chemotactic stimulation was prevented by anti-CD18 mAb, R15.7. These mechanisms may be operative at the endothelial interface in the transition of neutrophil behavior from rolling to stationary adhesion.

In our previous studies, optimum adhesion of neutrophils to endothelial cells under flow occurred only when previously unstimulated neutrophils were passed over IL- $1 \beta$ or LPS stimulated endothelial cells $(12-14,18,34)$. Greater than $60 \%$ of the adhesion appeared to be the result of neutrophil L-selectin as evidenced by the findings that $\mathrm{mAbs}$ to L-selectin cause $>60 \%$ inhibition, mAbs against the $\beta_{2}$-integrins (CD1 la/CD18 and $\mathrm{CD} 1 \mathrm{lb} / \mathrm{CD} 18)$ were without effect, chemotactic stimulation under conditions shown to shed surface L-selectin caused $>60 \%$ inhibition of adhesion, and a high degree of correlation was found between the levels of L-selectin on the surface of partially stimulated neutrophils and their adhesion under flow (13). An adhesive function for neutrophil L-selectin has also been argued to occur in vivo $(16,17)$, and the surface levels of neutrophil L-selectin appear highly correlated with the extent of neutrophil rolling on cytokine-stimulated venules $(13,14)$. By using these same experimental protocols with L-ELAM monolayers, we have obtained in the present studies data that are remarkably similar to those on cytokine stimulated endothelial cell monolayers. These results raise the possibility that neutrophil L-selectin is involved in the adhesion of neutrophils to E-selectin.

Kishimoto et al. (29) and Picker et al. (32) have raised the possibility that L-selectin and E-selectin contribute to a common adhesive pathway, explained by two interesting findings. L-selectin on neutrophils is decorated with $\operatorname{sLe}^{x}(32)$, a putative natural ligand for E-selectin (36), and L-selectin is not randomly distributed on the surface of neutrophils. Rather, L-selectin appears to be concentrated on the tips of surface projections from unstimulated neutrophils (32), a position that is particularly advantageous for early contact with counterreceptors on the surface of endothelial cells. The results in the present report are consistent with the idea that L-selectin and E-selectin interact under flow conditions, and thereby account for a significant portion of the adhesion seen between neutrophils and L-ELAM cell monolayers at the wall shear stress used in these experiments. The following results support this interpretation: (a) Anti-E-selectin mAb, CL2/6, was almost completely inhibitory indicating that the primary adhesion in this setting is E-selectin dependent. ( $b$ ) Pretreatment of the neutrophil with neuraminidase under conditions that almost abolished binding of CsLeX mAb (without affecting the levels of L-selectin on the neutrophils) prevented this adhesion.
This finding is also consistent with a primarily E-selectin-dependent mechanism since sialic acid is a necessary residue for high affinity binding of sLe ${ }^{x}$ by E-selectin (36). (c) Anti-L-selectin $\mathrm{mAb}$ inhibits this adhesion by $\sim 70 \%$. The basis for this inhibition is unlikely to be due to the antibody's ability to block the lectin function of L-selectin since there was no evidence that L-selectin recognized a carbohydrate structure on the control L cells or L-ICAM cells, and since neuraminidase pretreatment of the neutrophils also reduced neutrophil adhesion to an equal or greater degree. Two possible explanations are that when DREG-56 is bound to the neutrophil, it physically hinders E-selectin's ability to bind to sLe ${ }^{x}$ on L-selectin, or it activates the neutrophil to induce the same mechanism of reduced adhesion as chemokinetic stimulation ( see below). However, as pointed out in the results, we have been unable to show that DREG-56 signals the neutrophil for altered behavior.

Stimulation of neutrophils with different chemotactic factors $(11-14,29,47,48)$ under conditions that induce shedding of L-selectin from the neutrophil surface (without a significant reduction of CsLeX $\mathrm{mAb}$ binding) inhibited adhesion to both L-ELAM or activated HUVEC to the same degree as the anti$\mathrm{L}$-selectin mAb. The observation that removal of L-selectin can be accomplished without significant reductions in cell surface $\mathrm{sLe}^{\mathrm{x}}$ may be accounted for by the fact that L-selectin contains only a small percentage of total cell sLe ${ }^{x}(32)$. It must be pointed out that the use of FMLP stimulation to manipulate neutrophil adhesion is difficult to interpret since the activation may be superimposed on potential activation of the neutrophils by the M199 in which the cells are suspended. This culture medium contains micromolar ATP, a concentration that has been found to activate neutrophils via their $\mathrm{P}_{2}$ purinoreceptors (49-51). In addition, the loss of L-selectin may only be a marker of activation, with coincident loss of some other relevant ligand for E-selectin accounting for the reduced adhesion. However, given the findings that anti-L-selectin gives essentially the same degree of reduced adhesion as the FMLP stimulation under the current experimental conditions, and anti-Eselectin reveals an L-selectin-independent mechanism for adhesion of neutrophils to both L-ELAM and activated HUVEC, it remains a reasonable interpretation that FMLP, C5a, and platelet-activating factor each reduce adhesion of neutrophils under conditions of flow by reducing the surface levels of L-selectin $(11-14,29)$.

A fifth issue possibly supporting direct interaction between $\mathrm{L}$ - and E-selectin is the result using neonatal neutrophils. These cells have reduced surface levels of L-selectin (14), and show a reduced level of adhesion to L-ELAM cell monolayers that is proportional to the surface level of $\mathrm{L}$-selectin. The correlation between surface L-selectin and adhesion under flow was much stronger than the correlation between total surface levels of sLe $^{x}$ and adhesion. It remains possible that another ligand for E-selectin (e.g., CD66) (52) changes in unison with L-selectin on neonatal cells, and our analysis only creates the illusion that L-selectin is involved. The fact that the reduction in adhesion of neonatal neutrophils to activated HUVEC was of the same degree as to L-ELAM suggests that similar mechanisms are involved.

The results in this report are consistent with the interpretation that most of the adhesion of neutrophils to cytokine-stimulated HUVEC monolayers under conditions of flow in vitro involves L-selectin and E-selectin. There appears to be at least 
three patterns of interactions involving these selectins: L-selectin-dependent, E-selectin-independent adhesion; L-selectinindependent, E-selectin-dependent adhesion; and interactions of E- and L-selectin. In our experimental model with cytokinestimulated HUVEC monolayers, the first of these patterns seems to be most evident. Anti-L-selectin was much more inhibitory of neutrophil adhesion to activated endothelial cells under flow than anti-E-selectin suggesting that neutrophil Lselectin may recognize a structure on the activated endothelial cells that was not present on the L-ELAM monolayer. The relative contribution of the L-selectin-dependent component of this adhesion is consistently greater than the L-selectin-independent component. Watson et al. (17) found that a soluble recombinant form of $\mathrm{L}$-selectin exhibited antiinflammatory activity in mice, and proposed that this effect was due to competition for a ligand expressed on activated endothelial cells at the site of inflammation. In our model using E-selectin-transfected L cells, interaction of E- and L-selectin seems to be most evident. In contrast, the experimental strategies that restricted L-selectin's contribution to adhesion under flow were not as effective in this E-selectin based adhesion as anti-E-selectin $\mathrm{mAb}$, suggesting that neutrophil L-selectin with its associated sLe $^{\mathbf{x}}$ cannot account for all of E-selectin's ability to catch flowing neutrophils. Other sLe ${ }^{x}$ bearing antigens, such as CD66, can be responsible for this L-selectin-independent adhesion (52). It remains to be seen which of these patterns will predominate in vivo in different vascular beds.

\section{Acknowledgments}

The expert technical assistance of Bonnie J. Hughes, Marcella E. Estrella, Caryl Lane, Sharon Krater, and Shirely B. Williams and the excellent secretarial assistance of Michelle Swarthout, Arnez Washington, and Carol L. McGary are gratefully acknowledged. The contribution of the nursing staff of the Labor and Delivery Ward of Ben Taub General Hospital in providing the human umbilical cords and neonatal cord blood samples, without which this work would have not been possible, is greatly appreciated.

This work was supported in part by National Institutes of Health grants AI-19031, AI-23521, HL-18762, HL-42550, and NS-23327, and grant C938 from Robert A. Welch Foundation.

\section{References}

1. Atherton, A., and G. V. R. Born. 1972. Quantitative investigations of adhesiveness of circulating polymorphonuclear leukocytes to blood vessel wall. $J$. Physiol. (Lond.). 222:447-474.

2. Atherton, A., and G. V. R. Born. 1973. Relationship between the velocity of rolling granulocyte and that of the blood flow in venules. J. Physiol. (Lond.). 233:157-165.

3. Fiebig, E., K. Ley, and K. E. Arfors. 1991. Rapid leukocyte accumulation by "spontaneous" rolling and adhesion in the exteriorized rabbit rabbit mesentery. Int. J. Microcirc. Clin. Med. 10:127-144.

4. Ley, K., E. Lundgren, E. Berger, and K. E. Arfors. 1989. Shear-dependent inhibition of granulocyte adhesion to culture endothelium by dextran sulfate. Blood 73:1324-1330.

5. Ley, K., M. Cerrito, and K. E. Arfors. 1991. Sulfated polysaccharides inhibit leukocyte rolling in rabbit mesentery venules. Am. J. Physiol. 260:H1667H1673.

6. Kvietys, P. R., M. A. Perry, T. S. Gaginella, and D. N. Granger. 1990. Ethanol enhances leukocyte-endothelial cell interactions in mesenteric venules. Am. J. Physiol. 259:G57-G583.

7. House, S. D., and H. H. Lipowsky. 1987. Leukocyte-endothelial adhesion: microhemodynamics in mesentary of the cat. Microvasc. Res. 34:363-379.

8. Firrell, J. C., and H. H. Lipowsky. 1989. Leukocyte margination and deformation in mesenteric venules of rat. Am. J. Physiol. 256:H1667-H1674.

9. Lewinsohn, D. M., R. F. Bargatze, and E. C. Butcher. 1987. Leukocyte-en- dothelial cell recognition: evidence of a common molecular mechanism sharded by neutrophils, lymphocytes and other leukocytes. J. Immunol. 138:4313-4321.

10. Jutila, M. A., L. Rott, E. L. Berg, and E. C. Butcher. 1989. Function and regulation of the neutrophil MEL-14 antigen in vivo: comparison with LFA-1 and Mac-1. J. Immunol. 143:3318-3324.

11. Kishimoto, T. K., M. A. Jutila, E. L. Berg, and E. C. Butcher. 1989. Neutrophil Mac-1 and MEL-14 adhesion proteins inversely regulated by chemotactic factors. Science (Wash. DC). 245:1238-1241.

12. Abbassi, O., C. L. Lane, S. Krater, T. K. Kishimoto, D. C. Anderson, L. V. McIntire, and C. W. Smith. 1991. Canine neutrophil margination mediated by lectin adhesion molecule-1 (LECAM-1) in vitro. J. Immunol. 174:2107-2115.

13. Smith, C. W., T. K. Kishimoto, O. Abbassi, B. Hughes, R. Rothlein, L. V. McIntire, E. C. Butcher, and D. C. Anderson. 1991. Chemotactic factors regulate lectin adhesion molecule 1 (LECAM-1)-dependent neutrophil adhesion to cytokine-stimulated endothelial cells in vitro. J. Clin. Invest. 87:609-618.

14. Anderson, D. C., O. Abbassi, T. K. Kishimoto, J. M. Koenig, L. V. McIntire, and C. W. Smith. 1991. Diminished Lectin-, epidermal growth factor-, complement binding domain-cell adhesion molecule- 1 on neonatal neutrophils underlies their impaired CD18-independent adhesion to endothelial cells in vitro. $J$. Immunol. 146:3372-3379.

15. von Andrian, U. H., J. D. Chamber, L. M. McEvoy, R. F. Bargatze, K. E. Arfors, and E. C. Butcher. 1991. Two step model of leukocyte-endothelial cell interaction in inflammation: distinct roles for LECAM-1 and leukocyte beta2 integrins in vivo. Proc. Natl. Acad. Sci. USA. 88:7538-7542.

16. Ley, K., P. Gaehtgengs, C. Fennie, M. S. Singer, L. A. Lasky, and S. D. Rosen. 1991. Lectin-like cell adhesion molecule 1 mediates leukocyte rolling in mesenteric venules in vivo. Blood 77:2553-2555.

17. Watson, S. R., C. Fennie, and L. A. Lasky. 1991. Neutrophil influx into an inflammatory site inhibited by a soluble homing receptor-IgG chimera. Nature (Lond.). 349:164-167.

18. Lawrence, M. B., C. W. Smith, S. G. Eskin, and L. V. McIntire. 1990. Effect of venous shear stress on CD18-mediated neutrophil adhesion to cultured endothelium. Blood. 75:227-237.

19. Dustin, M. L., R. Rothlein, A. K. Bhan, C. A. Dinarello, and T. A. Springer. 1986. Induction by IL 1 and interferon-gamma: tissue distribution, biochemistry, and function of a natural adherence molecule (ICAM-1). J. Immunol. 137:245-254.

20. Pober, J. S., L. A. Lapierre, A. H. Stolpen, T. A. Brock, T. A. Springer, W. Fiers, M. P. Bevilacqua, D. L. Mendrick, and M. A. Gimbrone, Jr. 1987. Activation of cultured human endothelial cells by recombinant lymphotoxin: comparison with tumor necrosis factor and interleukin 1 species. J. Immunol. 138:33193324 .

21. Bevilacqua, M. P., S. Stengelin, M. A. Gimbrone, Jr., and B. Seed. 1989. Endothelial leukocyte adhesion molecule 1: an inducible receptor for neutrophils related to complement regulatory proteins and lectins. Science (Wash. DC). 243:1160-1165.

22. Weller, A., S. Isenmann, and D. Vestweber. 1992. Cloning of mouse endothelial selectins: expression of both E- and P-selectin is inducible by tumor necrosis factor-alpha. J. Biol. Chem. 267:15176-15183.

23. Spertini, O., F. W. Luscinskas, G. S. Kansas, J. M. Munro, J. D. Griffin, M. A. Gimbrone, and T. F. Tedder. 1991. Leukocyte adhesion molecule-1 (LAM-1, L-selectin) interacts with an insucible endothelial cell ligand to support leukocyte adhesion. J. Immunol. 147:2565-2573.

24. Mulligan, M. S., J. Varani, M. K. Dame, C. L. Lane, C. W. Smith, D. C. Anderson, and P. A. Ward. 1991. Role of ELAM-1 in neutrophil-mediated lung injury in rats. J. Clin. Invest. 88:1396-1406.

25. Gundel, R. H., C. D. Wagner, C. A. Torcellini, C. C. Clarke, N. Haynes, R. Rothlein, C. W. Smith, and L. G. Letts. 1991. Endothelial-leukocyte adhesion molecule-1 mediates antigen-induced acute airway inflammation and late-phase air way obstruction in monkeys. J. Clin. Invest. 88:1407-1411.

26. Entman, M. L., K. Youker, S. B. Shappell, C. Seigel, R. Rothlein, W. J. Dreyer, F. C. Schmalstieg, and C. W. Smith. 1990. Neutrophil adherence to isolated adult canine myocytes: evidence for a CD18-dependent mechanism. $J$. Clin. Invest. 85:1497-1506.

27. Sanchez-Madrid, F., J. Nagy, E. Robbins, P. Simon, and T. A. Springer. 1983. A human leukocyte differentiation antigen family with distinct alpha subunits and a common beta subunit: the lymphocyte function associated antigen (LFA-1), the C3bi complement receptor (OKM1/Mac-1), and the p150,95 molecule. J. Exp. Med. 158:1758-1803.

28. Kishimoto, T. K., M. A. Jutila, and E. C. Butcher. 1990. Identification of a human peripheral lymph node homing receptor: a rapidly down-regulated adhesion molecule. Proc. Natl. Acad. Sci. USA. 87:2244-2248.

29. Kishimoto, T. K., R. A. Warnock, M. A. Jutila, E. C. Butcher, C. L. Lane, D. C. Anderson, and C. W. Smith. 1991. Antibodies against human neutrophil LECAM-1 (LAM-1/Leu-8/DREG-56 antigen) and endothelial cells ELAM-1 inhibit a common CD18-independent adhesion pathway in vitro. Blood. 78:805811 .

30. Parham, P. 1983. On the fragmentation of the monoclonal IgG1, IgG2a and IgG2b from BALB/c mice. J. Immunol. 131:2895-2902. 
31. Smith, C. W., S. D. Marlin, R. Rothlein, C. Toman, and D. C. Anderson. 1989. Cooperative interactions of LFA-1 and Mac-1 with intercellular adhesion molecule- 1 in facilitating adherence and transendothelial migration of human neutrophils in vitro. J. Clin. Invest. 83:2008-2017.

32. Picker, L. J., R. A. Warnock, A. R. Burns, C. M. Doerschuk, E. L. Bergs, and E. C. Butcher. 1991. The neutrophil selectin LECAM-1 presents carbohydrate ligands to the vascular selectin ELAM-1 and GMP-140. Cell. 66:921-933.

33. Ausubel, F. M., R. Brent, R. D. Kingston, D. D. Moore, J. G. Seidman, J. A. Smith, and K. Struhl. 1987. Current Protocals in Molecular Biology. Green Publishing Associates and Wiley-Interscience, New York.

34. Smith, C. W., S. D. Marlin, R. Rothlein, M. B. Lawrence, L. V. McIntire, and D. C. Anderson. 1989. Role of ICAM-1 in the adherence of the human neutrophils to human endothelial cells in vitro. In Leukocyte Adhesion Molecules; Structure, Function, and Regulation. T. A. Springer, D. C. Anderson, R. Rothlein, and A. S. Rosenthal, editors. Springer-Verlag, Inc., New York. 170189.

35. Waltz, G., A. Aruffo, W. Kolanus, M. Bevilacqua, and B. Seed. 1990. Recognition by ELAM-1 of Sialyl-Lex determinant on myeloid and tumor cells. Science (Wash. DC). 250:1132-1135.

36. Phillips, M. L., E. Nudelman, F. C. Gaeta, M. Perez, A. K. Singhal, S. Hakomori, and J. C. Paulson. 1990. ELAM-1 mediates cell adhesion by recognition of a carbohydrate ligand, sialyl-Lex. Science (Wash. DC). 250:1130-1132.

37. Anderson, D. C., O. Abbassi, J. D. Fortenberry, J. M. Koenig, and C. W. Smith. 1993. Abnormalities of LECAM-1 and Mac-1-dependent neutrophil-endothelial cell adhesion in the developing host. In Structure and Function of Molecules Involved in Leukocyte Adhesion. Volume II. P. E. Lipsky, R. Rothlein T. K. Kishimoto, R. B. Faanes, and C. W. Smith, editors. Springer-Verlag, Inc., New York. 337-355.

38. Perry, M. A., and D. N. Granger. 1991. Role of CD11/CD18 in shear rate-dependent leukocyte-endothelial cell interactions in cat mesenteric venules. J. Clin. Invest. 87:1798-1804.

39. Hughes, B. J., J. C. Hollers, E. Crockett-Torabi, and C. W. Smith. 1992 Recruitment of CD11b/CD18 to the neutrophil surface and adherence-dependent cell locomotion. J. Clin. Invest. 90:1687-1696.

40. Diamond, M. S., D. E. Staunton, A. R. deFougerolles, S. A. Stacker, A. J. Garcia, M. L. Hibbs, and T. A. Springer. 1990. ICAM-1 (CD54): a counter receptor for Mac-1 (CD11b/CD18). J. Cell Biol. 111:3129-3139.

41. Bevilacqua, M. P., J. S. Pober, D. L. Mendrick, R. S. Cotran, and M. A. J. Gimbrone. 1987. Identification of an inducible endothelial-leukocyte adhesion molecule. Proc. Natl. Acad. Sci. USA. 84:9238-9242.

42. Lawrence, M. B., and T. A. Springer. 1991. Leukocytes roll on a selectin at physiologic flow rates: distinction from a prerequisite for adhesion through integrins. Cell. 65:859-873.

43. Furie, M. B., M. J. Burns, M. C. A. Tancinco, C. D. Benjamin, and R. R. Lobb. 1992. E-selectin (endothelial-leukocyte adhesion molecule-1) is not required for the migration of neutrophils across IL-1-stimulated endothelium in vitro. J. Immunol. 148:2395-2404.

44. Hakkert, B. C., T. W. Kuijpers, J. F. M. Leeuwenberg, J. A. van Mourik, and D. Roos. 1991. Neutrophil and monocyte adherence to and migration across monolayers of cytokine-activated endothelial cells: the contribution of CD18 ELAM-1, and VLA-4. Blood. 78:2721-2726.

45. Luscinskas, F. W., M. I. Cybulsky, J-M. Kiely, C. S. Peckins, V. M. Davis, and M. A. Gimbrone. 1991. Cytokine-activated human endothelial monolayers support enhanced neutrophil transmigration via a mechanism involving both endothelial-leukocyte adhesion molecule- 1 and intercellular adhesion molecule1. J. Immunol. 146:1617-1625.

46. Lo, S. K., S. Lee, R. A. Ramos, R. Lobb, M. Rosa, G. Chi-Rosso, and S. D. Wright. 1991. Endothelial-leukocyte adhesion molecule 1 stimulates the adhesive activity of leukocyte integrin CR3 (CD1 1b/CD18, Mac-1, $\left.\alpha_{\mathrm{m}} \beta_{2}\right)$ on human neutrophils. J. Exp. Med. 173:1493-1500.

47. Griffin, J. D., O. Spertini, T. J. Ernst, M. P. Belvin, H. B. Levine, Y. Kanakura, and T. F. Tedder. 1990. Granulocyte-macrophage colony-stimulating factor and other cytokines regulate surface expression of the leukocyte adhesion molecule-1 on human neutrophils, monocytes, and their precursors. J. Immunol. 145:576-584.

48. Jutila, M. A., T. K. Kishimoto, and E. C. Butcher. 1990. Regulation and lectin activity of the human neutrophil peripheral lymph node homing receptor. Blood. 76:178-83.

49. Cowen, D. S., H. M. Lazarus, S. B. Shurin, S. E. Stoll, and G. R. Dubyak. 1989. Extracellular adenosine triphosphate activates calcium mobilization in human phagocytic leukocytes and neutrophil/monocyte progenitor cells. J. Clin. Invest. 83:1651-1660.

50. Ward, P. A., T. W. Cunningham, K. K. McCulloch, and K. W. Johnson. 1988. Regulatory effects of adenosine and adenine nucleotides on exygen radical responses of neutrophils. Lab. Invest. 58:438-447.

51. Kuhns, D. B., D. G. Wright, J. Nath, S. S. Kaplan, and R. E. Basford 1988. ATP induces transient elevations in $\left[\mathrm{Ca}^{2+}\right]_{i}$ in human neurophils and primes these cells for enhanced $\mathrm{O}_{2}^{-}$generation. Lab. Invest. 58:448-453.

52. Kuijpers, T. W., M. Hoogerwerf, L. J. W. van der Laan, G. Nagel, C. E. van der Schoot, F. Grunert, and D. Roos. 1992. CD66 nonspecific cross-reacting antigens are involved in neutrophil adherence to cytokine-activated endothelial cells. J. Cell Biol. 118:457-466. 